\title{
Effect of Maxima Suppressor and Supporting Electrolyte on Polarographic Wave of Dimethyl Sulfoxide and its Determination
}

\section{Swaroopa Rani N Gupta*}

Department of Chemistry, Brijlal Biyani Science College, Amravati, Maharashtra, India

\begin{abstract}
The oxidation of the biologically very important dimethyl sulfoxide system has been the subject of investigations. In present study Dimethyl sulfoxide (DMSO) can be oxidized to dimethyl sulfone by anodic electrolysis at a rotating platinum electrode. The polarographic method has been used to study qualitatively the effect of maxima suppressor gelatin, fuchsin, methyl red, thymol blue and supporting electrolyte $\mathrm{HCl}, \mathrm{CH}_{3} \mathrm{COOH}$ on oxidation wave of DMSO. Polarographic oxidation of DMSO in $0.1 \mathrm{M} \mathrm{HCl}, 0.1 \mathrm{M} \mathrm{CH}_{3} \mathrm{COOH}$ solution using optimum concentration of fuchsin, methyl red, thymol blue as surface active substances is followed to determine the DMSO present in synthetic sample by calibration method. Wave analysis indicate the irreversible nature of the oxidation process which involves oxidation of dimethyl sulfoxide to dimethyl sulfone thereby increasing the oxidation state of sulphur from +2 to +4 state.
\end{abstract}

Keywords: $\mathrm{CH}_{3} \mathrm{COOH}$; Dimethyl sulfoxide; Fuchsin; $\mathrm{HCl}$; Methyl red; Thymol blue

\section{Introduction}

The first quality that struck Dr. Jacob about the DMSO drug was its ability to pass through membranes, an ability that has been verified by numerous subsequent researchers [1]. DMSO perhaps has been used most widely as a topical analgesic, in a 70 percent DMSO, 30 percent water solution. Laboratory studies suggest that DMSO cuts pain by blocking peripheral nerve $\mathrm{C}$ fibers [2]. Several clinical trials have demonstrated its effectiveness $[3,4]$, although in one trial, no benefit was found [5]. DMSO reduces inflammation by several mechanisms. It is an antioxidant, a scavenger of the free radicals that gather at the site of injury. This capability has been observed in experiments with laboratory animals [6] and in 150 ulcerative colitis patients in a double-blinded randomized study in Baghdad, Iraq [7]. Yet laboratory studies have indicated that DMSO's capacity as a free-radical scavenger suggests an important role for it in arthritis [8]. The Committee of Clinical Drug Trials of the Japanese Rheumatism Association conducted a trial with 318 patients at several clinics using 90 percent DMSO and concluded that DMSO relieved joint pain and increased range of joint motion and grip strength, although performing better in more recent cases of the disease [9]. It is employed widely in the former Soviet Union for all the different types of arthritis, as it is in other countries around the world. DMSO also stabilized blood pressure, improved respiration, and increased urine output by five times and increased blood flow through the spinal cord to areas of injury [10-12]. DMSO has long been used to promote healing. People who have it on hand often use it for minor cuts and burns and report that recovery is speedy. Several studies have documented DMSO use with soft tissue damage, local tissue death, skin ulcers, and burns [13-16]. In relation to cancer, several properties of DMSO have gained attention. In one study with rats, DMSO was found to delay the spread of one cancer and prolong survival rates with another [17]. A chemoreductionpurge-and-trap gas chromatographic method has been developed for the determination of trace dimethylsulfoxide (DMSO) in seawater [18]. Dimethyl sulphoxide and methylsulfonylmethane are two related nutritional supplements used for symptomatic relief of osteoarthritis. A meta-analysis was conducted to evaluate their efficacy in reducing pain associated with osteoarthritis [19].

Dimethyl sulfoxide is colourlesss hygroscopic liquid, soluble in water, alcohol, benzene, acetone and chloroform. It readily penetrates skin and other tissues hence being extensively tested as a means of carrying drugs and antitoxins into the blood by topical application, medicine (anti-inflammatory), veterinary medicine, plant pathology and nutrition, pharmaceutical products, metal - complexing agent. It is used as a powerful solvent with low toxicity, of increasing importance, for synthetic fibers especially polyacrylonitrile fibers, industrial cleaners, pesticides, paint stripping, as a reaction medium, for hydraulic fluids, preservation of cells at low temperatures.

The oxidation of the biologically very important dimethyl sulfoxide system has been the subject of investigations. In present study Dimethyl sulfoxide (DMSO) can be oxidized to dimethyl sulfone by anodic electrolysis at a rotating platinum electrode. The polarographic method has been used to study qualitatively the effect of maxima suppressor gelatin, fuchsin, methyl red, thymol blue and supporting electrolyte $\mathrm{HCl}, \mathrm{CH}_{3} \mathrm{COOH}$ on oxidation wave of DMSO. Polarographic oxidation of DMSO in $0.1 \mathrm{M} \mathrm{HCl}, 0.1 \mathrm{M} \mathrm{CH}_{3} \mathrm{COOH}$ solution using optimum concentration of fuchsin, methyl red, thymol blue as surface active substances is followed to determine the DMSO present in synthetic sample by calibration method.

\section{Methodology}

All chemicals were of A.R. grade. Solvent were purified before use. Sulfoxide samples were synthesized from A.R. grade chemicals. D.C. Recording polarograph along with OmniScribe recorder were, used to record the polarogram using Rotating Platinum Electrode (R.P.E.) and Saturated Calomel Electrode (S.C.E.) as an anode and cathode respectively. $50 \mathrm{ml}$ total volume was maintained for each measurement.

\section{Effect of maxima suppressor and supporting electrolyte on polarographic wave of dimethyl sulfoxide}

The maxima suppressor capacity of gelatin, fuchsin, methyl red and thymol blue on anodic wave of Dimethyl sulfoxide in presence of

*Corresponding author: Swaroopa Rani N. Gupta, Department of Chemistry, Brijlal Biyani Science College, Amravati, Maharashtra, India, Tel: +919665041291; E-mail: swargupta@yahoo.com

Received January 11, 2016; Accepted January 23, 2016; Published January 25 2016

Citation: Gupta SRN (2016) Effect of Maxima Suppressor and Supporting Electrolyte on Polarographic Wave of Dimethyl Sulfoxide and its Determination. Med chem 6: 053-057. doi:10.4172/2161-0444.1000324

Copyright: (c) 2016 Gupta SRN. This is an open-access article distributed under the terms of the Creative Commons Attribution License, which permits unrestricted use, distribution, and reproduction in any medium, provided the original author and source are credited. 
different supporting electrolytes viz. $0.1 \mathrm{M} \mathrm{HCl}$ and $0.1 \mathrm{M} \mathrm{CH}_{3} \mathrm{COOH}$ was studied. Systems were prepared by taking an aliquot of Dimethyl sulfoxide solution, $1 \mathrm{ml} 5 \mathrm{M}$ supporting electrolyte and a definite amount of maxima suppressors $\left(1.25 \times 10^{-5} \mathrm{~g}\right.$ to $\left.1.625 \times 10^{-3} \mathrm{~g}\right)$ and diluted to $50 \mathrm{ml}$ with water. Polarogram of each system was recorded on D.C. Recording polarograph between 600 to $1600 \mathrm{mV}$ using R.P.E.S.C.E. system. Further experiments were carried out under similar conditions. Supporting electrolyte - maxima suppressor combinations as shown in Table 1 gave good results and was used for further determination of dimethyl sulfoxide.

\section{Polarographic determination of dimethyl sulfoxide (calibra- tion method)}

A calibration curve for $i_{d}$ as a function of concentration of dimethyl sulfoxide was prepared under different experimental condition as given in Table 1. The $\mathrm{i}_{\mathrm{d}}$ for the unknown was measured under corresponding experimental condition and the concentration was read out from the graph.

\section{Observation}

Effect of maxima suppressor and supporting electrolyte on polarographic wave of dimethyl sulfoxide

Maxima suppressor capacity of fuchsin, methyl red and thymol blue on the anodic wave of dimethyl sulfoxide in $0.1 \mathrm{M} \mathrm{HCl}$ medium are shown in Figures 1-3. Dimethyl sulfoxide produces good sigmoid anodic waves in presence of $0.1 \mathrm{M} \mathrm{HCl}$ as supporting electrolytes and suitable concentration of fuchsin, methyl red, thymol blue as maxima suppressors. The wave height increases with $\mathrm{pH}$ (Figure 4).

\section{Polarographic determination of dimethyl sulfoxide (calibra-} tion method)

Figures 5-9 display polarographic determination of Dimethyl sulfoxide by Calibration method. Respective calibration data is shown in Table 2. The table presents various concentration of dimethyl sulfoxide in different supporting electrolyte - maxima suppressor system. Diffusion currents were measured at indicated potential vs S.C.E. and corrected for the residual current of the blank.

\section{Results and Dicussion}

Effect of maxima suppressors on polarographic waves of dimethyl sulfoxide

Surfactant mainly gelatin, fuchsin, methyl red and thymol blue are added to obtain smooth, easily measurable limiting currents in $0.1 \mathrm{M}$ $\mathrm{HCl} / \mathrm{CH}_{3} \mathrm{COOH}$ as supporting electrolyte. The use of gelatin (in 0.1 $\mathrm{M} \mathrm{HCl} / \mathrm{CH}_{3} \mathrm{COOH}$ ), fuchsin, methyl red and thymol blue (in $0.1 \mathrm{M}$ $\mathrm{CH}_{3} \mathrm{COOH}$ ) are found to give unsatisfactory result in which cases rising portion of wave suppresses due to the increase in viscosity with increasing concentration of maxima suppressors but there are no distinction between diffusion current and limiting current plateau even at high concentrations of surfactants.

The effect of fuchsin, methyl red and thymol blue in $0.1 \mathrm{M} \mathrm{HCl}$ is particularly important which is shown in Figures 1-3. When their concentration is very small $\left(\leq 2.5 \times 10^{-5} \%\right)$ the wave almost run parallel with the wave obtained in the absence of these surfactant. Apparently, at these small concentrations the fuchsin/methyl red/thymol blue is unable to prevent the streaming movement of the diffusion layer at the electrode-solution interface completely. With increasing their concentration the adsorption of them is apparently favored, and dependent on the concentration of fuchsin/methyl red/thymol blue, the current decreases and well defined limiting current plateau is obtained.
In all these cases it is observed that the wave obtained in solutions free of dimethyl sulfoxide crosses limiting current region of DMSO wave. This indicates that oxidation of blank species predominates at limiting current region of dimethyl sulfoxide wave which restricts the wave in attaining the well defined limiting current plateau. $2.5 \times 10^{-5} \%$ funchsin $/ 2.5$ $\times 10^{-4} \%$ methyl red $/ 1.25 \times 10^{-3} \%$ thymol blue is found to produce optimum result. Decomposition potential is found to be constant at $\sim 800 \mathrm{mV}$ with varying concentrations of the surface active substances.

\section{Effect of supporting electrolytes on polarographic waves of dimethyl sulfoxide}

Effect of various concentrations of hydrochloric acid on the anodic wave of dimethyl sulfoxide in presence of $2.5 \times 10^{-5} \%$ fuchsin $/ 2.5$ $\times 10^{-4} \%$ methyl red $1.25 \times 10^{-3} \%$ thymol blue is found to produce similar result as shown in Figure 4. At former concentrations of hydrochloric acid, the apparent diffusion current found to increase as $\mathrm{HCl}$ concentration changes from 0.01 to $1 \mathrm{M}$, at the same time decomposition potential shifts to more negative potential. In 0.01 , 0.1 and $1 \mathrm{M} \mathrm{HCl}$ medium, the decomposition potential of dimethyl sulfoxide is found to be 844,812 and $800 \mathrm{mV}$ respectively as may be seen from Figure 4. At higher concentrations $(>1 \mathrm{M})$ of $\mathrm{HCl}$, the wave height decreases considerably due to decrease in the apparent diffusion coefficient; decomposition potential remains unaffected. The blank species predominates at limiting current region of dimethyl sulfoxide wave at higher concentrations of $\mathrm{HCl}$.

\section{Polarographic determination of dimethyl sulfoxide (calibra- tion method)}

Dimethyl sulfoxide gives a well defined wave in hydrochloric acid and to some extent in acetic acid. The waves are suitable for quantitative estimation. The precision of the linear relation between $\mathrm{i}_{\mathrm{d}}$ and $\mathrm{C}$ under

\begin{tabular}{|c|c|}
\hline Supporting electrolyte & Maxima suppressor \\
\hline $0.1 \mathrm{M} \mathrm{HCl}$ & $2.5 \times 10^{-5 \%}$ Fuchsin \\
\hline $0.1 \mathrm{M} \mathrm{HCl}$ & $2.5 \times 10^{-4} \%$ Methyl red \\
\hline $0.1 \mathrm{M} \mathrm{HCl}$ & $2.5 \times 10^{-4} \%$ Thymol blue \\
\hline $0.1 \mathrm{M} \mathrm{HCl}$ & - \\
\hline $0.1 \mathrm{M} \mathrm{CH}_{3} \mathrm{COOH}$ & - \\
\hline
\end{tabular}

Table 1: The optimum concentration of supporting electrolyte - maxima suppressor for determination of dimethyl sulfoxide by polarographic calibration method.

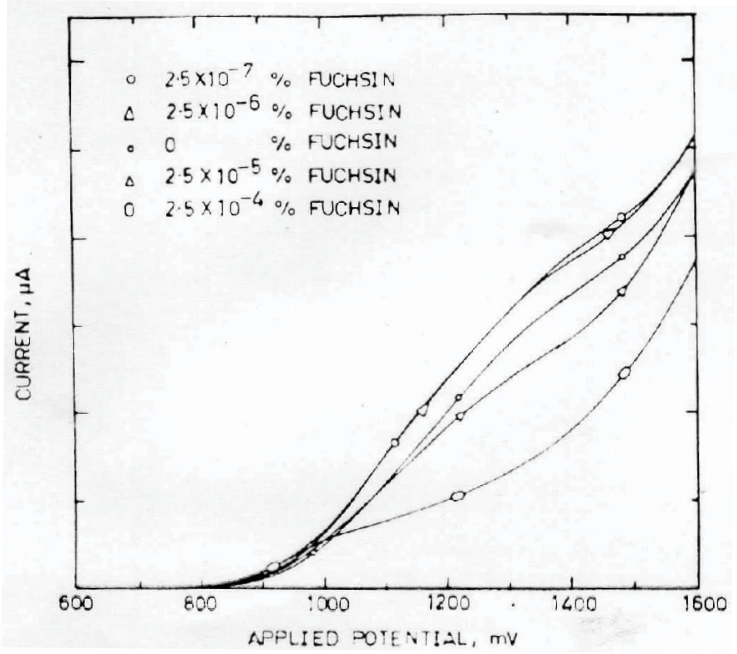

Figure 1: Effect of Fuchsin concentration on the anodic wave of $0.1 \mathrm{M}$ Dimethyl sulfoxide in $0.1 \mathrm{M} \mathrm{HCl}$. 
Citation: Gupta SRN (2016) Effect of Maxima Suppressor and Supporting Electrolyte on Polarographic Wave of Dimethyl Sulfoxide and its Determination. Med chem 6: 053-057. doi:10.4172/2161-0444.1000324

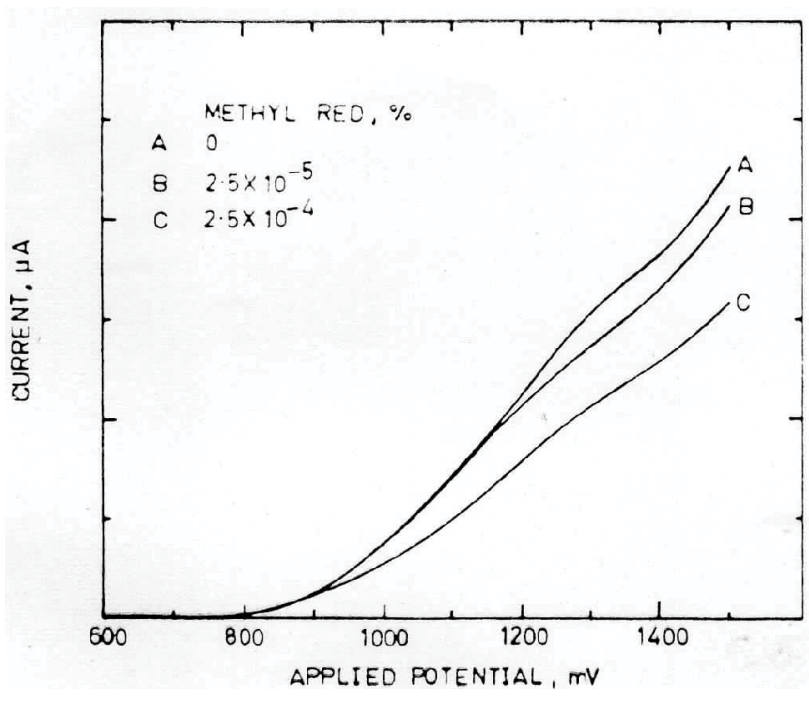

Figure 2: Effect of Methyl red concentration on the anodic wave of $0.1 \mathrm{M}$ Dimethyl sulfoxide in $0.1 \mathrm{M} \mathrm{HCl}$.

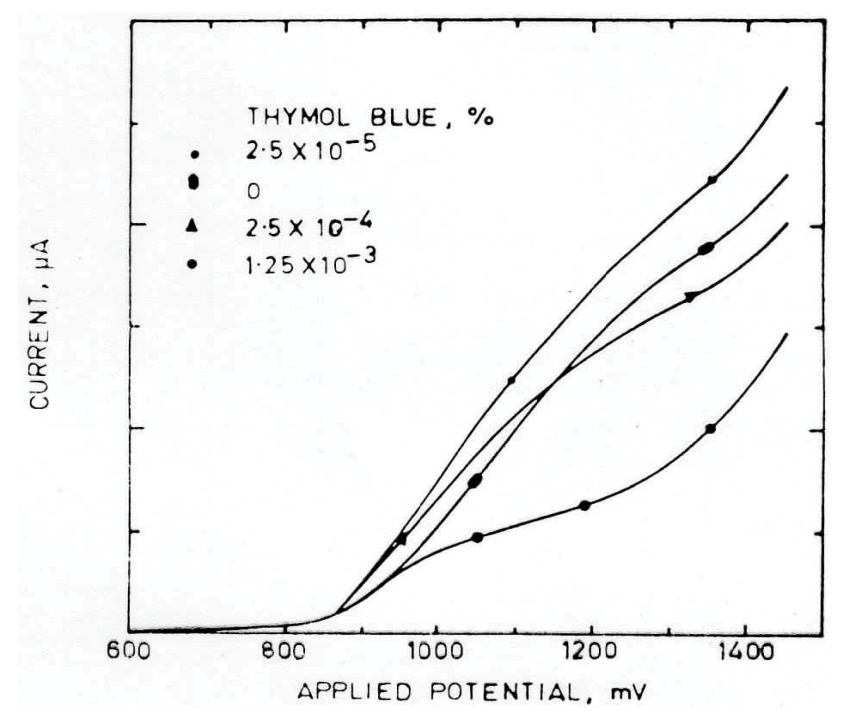

Figure 3: Effect of Thymol blue concentration on the anodic wave of $0.1 \mathrm{M}$ Dimethyl sulfoxide in $0.1 \mathrm{M} \mathrm{HCl}$.

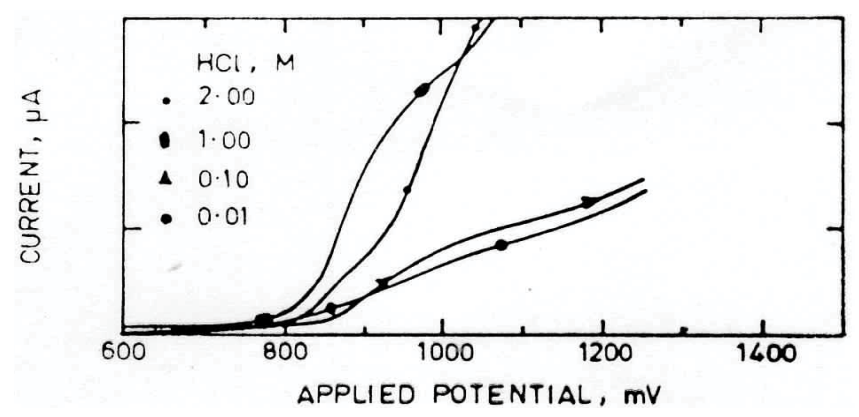

Figure 4: Effect of $\mathrm{HCl}$ concentration on the anodic wave of $0.1 \mathrm{M}$ Dimethyl sulfoxide in presence of $1.25 \times 10^{-3} \%$ Thymol blue.

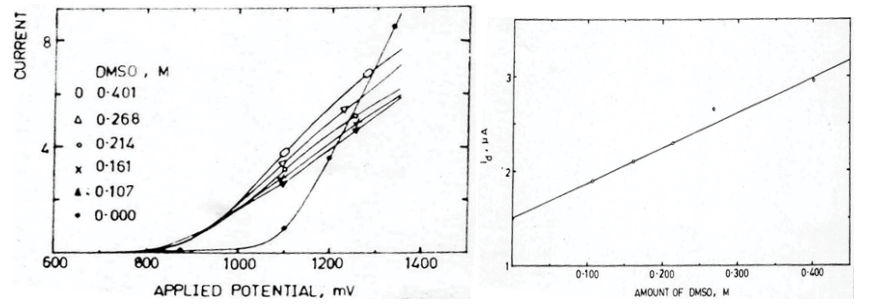

Figure 5 (A): Calibration polarogram for Dimethyl sulfoxide determination in $0.1 \mathrm{M} \mathrm{HCl}$ with $2.5 \times 10^{-5} \%$ Fuchsin. (B): Calibration curve for Dimethyl sulfoxide.
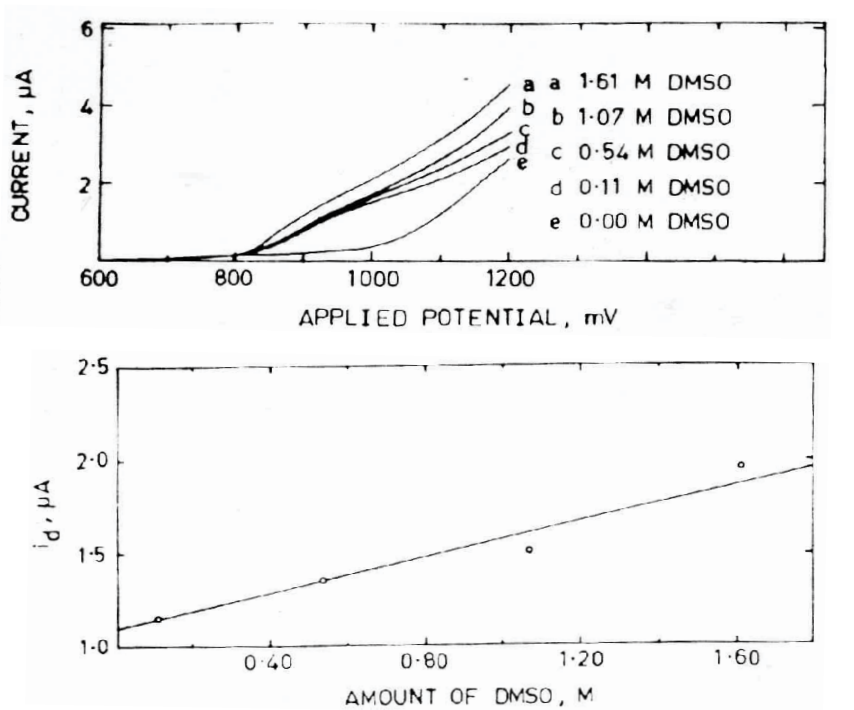

Figure 6 (A): Calibration polarogram for Dimethyl sulfoxide determination in $0.1 \mathrm{M} \mathrm{HCl}$ with $2.5 \times 10^{-4} \%$ Methyl red.(B): Calibration curve for Dimethyl sulfoxide

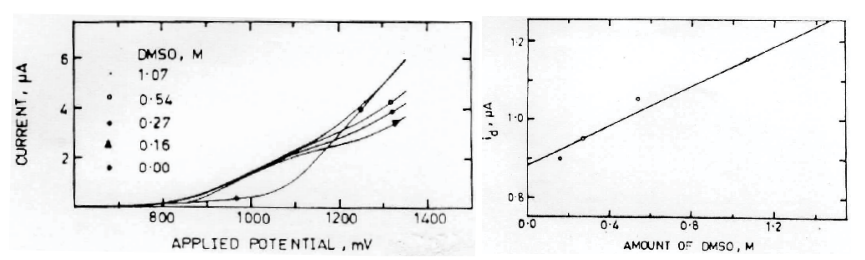

Figure 7 (A): Calibration polarogram for Dimethyl sulfoxide determination in $0.1 \mathrm{M} \mathrm{HCl}$ with $2.5 \times 10^{-4} \%$ Thymol blue. (B): Calibration curve for Dimethyl sulfoxide.
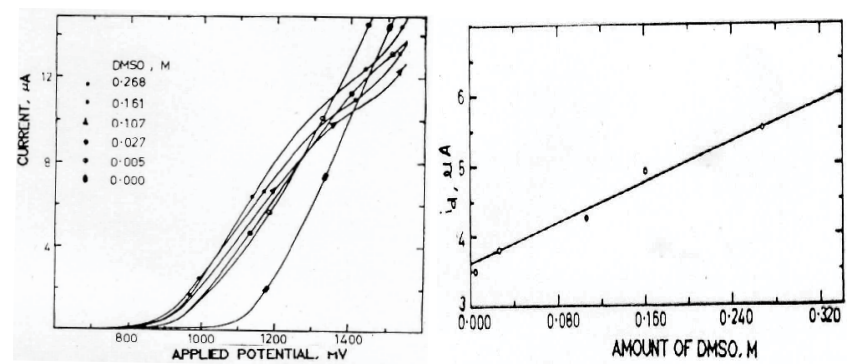

Figure 8 (A): Calibration polarogram for Dimethyl sulfoxide determination in $0.1 \mathrm{M} \mathrm{HCl}$. (B): Calibration curve for Dimethyl sulfoxide. 
Citation: Gupta SRN (2016) Effect of Maxima Suppressor and Supporting Electrolyte on Polarographic Wave of Dimethyl Sulfoxide and its Determination. Med chem 6: 053-057. doi:10.4172/2161-0444.1000324

favourable conditions is given by the data in Table 2. The DMSO produces an abnormally small limiting current in $0.1 \mathrm{M} \mathrm{HCl}$ or $0.1 \mathrm{CH}_{3} \mathrm{COOH}$, and the ration $\mathrm{i}_{\mathrm{d}} / \mathrm{C}$ decreases markedly with increasing concentration of DMSO. Hence in an unknown case it is always necessary to verify the relation between $i_{d}$ and $C$. This indicates that the limiting current is not diffusion controlled but is governed by the actual rate of the electrode reaction; hence the limiting current is not strictly as linear function of concentration even when correction is applied for the residual current.

The polarographic method has been used to follow the decomposition of DMSO in a $0.1 \mathrm{M}$ hydrochloric acid. A somewhat more steeply rising curves are obtained with a rotating platinum electrode as indicated in Figures 5-9. There is no strict proportionality between the diffusion current and the concentration of DMSO even when the proper correction is applied for the residual current. Plot of E against $\log \left(i_{d}-i\right) / i$ yields a straight line (Figure 10$)$. However, the slope of the log plot differs from the theoretical value $0.030 \mathrm{~V}$ for the oxidation process involving 2 number of electrons hence the value of $n$ calculated from the slope has no significance (Table 3) $E_{1 / 2}$ is not constant and depend on the concentration of the dimethyl sulfoxide. All these points indicate the irreversible nature of the oxidation process:

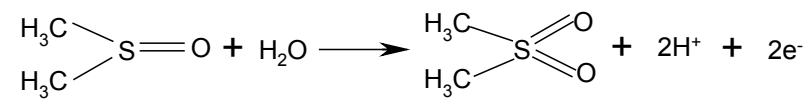

Which involves oxidation of dimethyl sulfoxide to dimethyl sulfone thereby increasing the oxidation state of sulfur from +2 to +4 state.

\section{Conclusion}

$2.5 \times 10^{-5} \%$ funchsin $/ 2.5 \times 10^{-4} \%$ methyl red $/ 1.25 \times 10^{-3} \%$ thymol blue is found to produce optimum result. Decomposition potential remains constant at $\sim 800 \mathrm{mV}$ with varying concentrations of surface active substances.

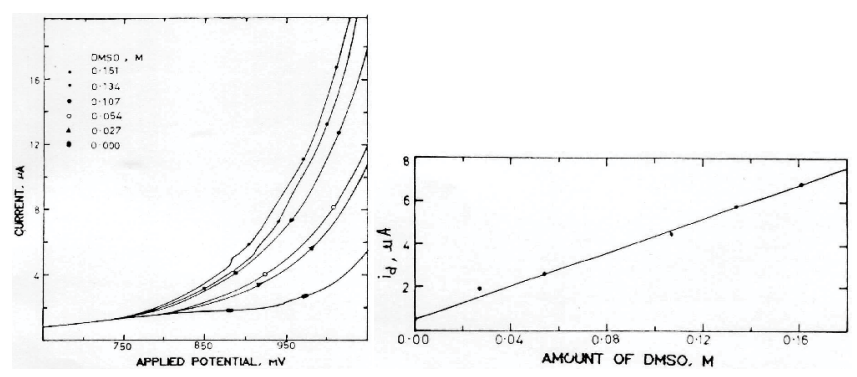

Figure 9 (A): Calibration polarogram for Dimethyl sulfoxide determination in $0.1 \mathrm{M} \mathrm{CH}_{3} \mathrm{COOH}$. (B): Calibration curve for Dimethyl sulfoxide.

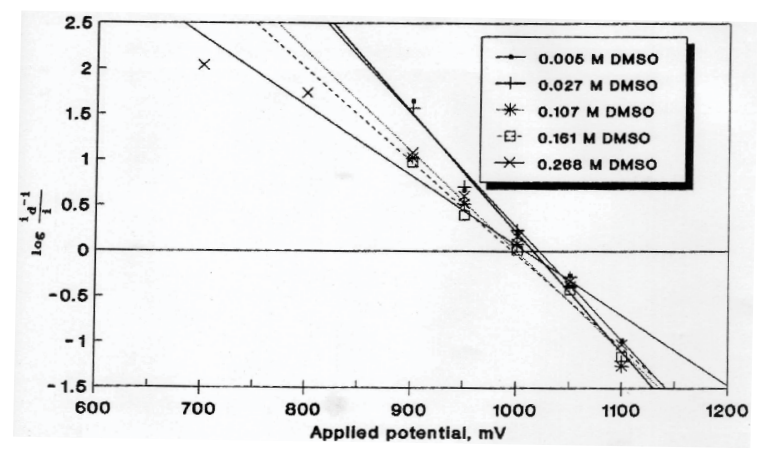

Figure 10: Log plots of the waves of Dimethyl sulfoxide at various concentratios in $0.1 \mathrm{M} \mathrm{HCl}$; Experimental points from Figure 8 (A).

\begin{tabular}{|c|c|c|c|}
\hline \multirow{2}{*}{ DMSO, M } & \multicolumn{2}{|l|}{$\mathbf{i}_{\mathrm{d}}$} & \multirow{2}{*}{$i_{d} / C$} \\
\hline & Observed & Corrected & \\
\hline \multicolumn{4}{|c|}{$0.1 \mathrm{M} \mathrm{HCl}-2.5 \times 10^{-5} \%$ Fuchsin At $1088 \mathrm{mV}$} \\
\hline 0 & 0.7 & - & - \\
\hline 0.107 & 2.6 & 1.9 & 17.8 \\
\hline 0.161 & 2.8 & 2.1 & 13 \\
\hline 0.214 & 3 & 2.3 & 10.7 \\
\hline 0.268 & 3.35 & 2.65 & 9.9 \\
\hline 0.401 & 3.65 & 2.95 & 7.4 \\
\hline \multicolumn{4}{|c|}{$0.1 \mathrm{M} \mathrm{HCl}-2.5 \times 10^{-4} \%$ Methyl red At $1050 \mathrm{mV}$} \\
\hline 0 & 0.65 & - & - \\
\hline 0.11 & 1.8 & 1.15 & 10.5 \\
\hline 0.54 & 2 & 1.35 & 2.5 \\
\hline 1.07 & 2.15 & 1.5 & 1.4 \\
\hline 1.61 & 2.6 & 1.95 & 1.2 \\
\hline \multicolumn{4}{|c|}{$0.1 \mathrm{M} \mathrm{HCl}-2.5 \times 10^{-4} \%$ Thymol Blue At $1100 \mathrm{mV}$} \\
\hline 0 & 1.15 & - & - \\
\hline 0.16 & 2.05 & 0.9 & 5.6 \\
\hline 0.27 & 2.1 & 0.95 & 3.5 \\
\hline 0.54 & 2.2 & 1.05 & 1.9 \\
\hline 1.07 & 2.3 & 1.15 & 1.1 \\
\hline \multicolumn{4}{|c|}{$0.1 \mathrm{M} \mathrm{HCl}$ - without maxima suppressor at $1150 \mathrm{mV}$} \\
\hline 0 & 1.3 & - & - \\
\hline 0.005 & 4.8 & 3.5 & 700 \\
\hline 0.027 & 5.1 & 3.8 & 140.7 \\
\hline 0.107 & 5.55 & 4.25 & 39.7 \\
\hline 0.161 & 6.2 & 4.9 & 30.4 \\
\hline 0.268 & 6.8 & 5.5 & 20.5 \\
\hline \multicolumn{4}{|c|}{$0.1 \mathrm{M} \mathrm{CH}_{3} \mathrm{COOH}$ - without maxima suppressor at $950 \mathrm{mV}$} \\
\hline 0 & 2.4 & - & - \\
\hline 0.027 & 4.3 & 1.9 & 70.4 \\
\hline 0.054 & 5 & 2.6 & 48.1 \\
\hline 0.107 & 6.9 & 4.5 & 42.1 \\
\hline 0.134 & 8.2 & 5.8 & 43.3 \\
\hline 0.161 & 9.2 & 6.8 & 42.2 \\
\hline
\end{tabular}

Table 3: Comparison of Theoretical and Experimental values of slope of log plots and $\mathrm{n}$ of Dimethyl sulfoxides at various concentrations in $0.1 \mathrm{M} \mathrm{HCl}$.

\begin{tabular}{|c|c|c|c|c|c|c|c|}
\hline \multirow{2}{*}{$\begin{array}{l}\text { DMSO, } \\
\text { M }\end{array}$} & \multirow{2}{*}{$\begin{array}{l}i_{d} \text { at } \\
1150 \\
m V\end{array}$} & \multirow[t]{2}{*}{$i_{d} / C$} & \multirow{2}{*}{$\begin{array}{l}\mathrm{E} 1 / 2, \\
\mathrm{mV}\end{array}$} & \multicolumn{2}{|c|}{$\begin{array}{l}\text { Slope of } \log \left(i_{d}-i\right) / \\
\text { i vs E Plots, } v\end{array}$} & \multicolumn{2}{|c|}{ value of $n$} \\
\hline & & & & Theo & Exptl & Theo & Exptl \\
\hline 0.005 & 3.4 & 680 & 1023 & \multirow{5}{*}{0.03} & 0.107 & \multirow{5}{*}{2} & 0.55 \\
\hline 0.027 & 3.8 & 141 & 1023 & & 0.101 & & 0.59 \\
\hline 0.107 & 4.3 & 40 & 1010 & & 0.11 & & 0.54 \\
\hline 0.161 & 4.95 & 31 & 999 & & 0.122 & & 0.48 \\
\hline 0.268 & 5.5 & 21 & 1015 & & 0.107 & & 0.55 \\
\hline
\end{tabular}

DMSO gives a well-defined wave in hydrochloric acid and to some extent in acetic acid. The waves are suitable for quantitative estimation.

Wave analysis indicate the irreversible nature of the oxidation process which involves oxidation of dimethyl sulfoxide to dimethyl sulfone thereby increasing the oxidation state of sulphur from +2 to +4 state.

\section{References}

1. Kolb KH, Jaenicke G, Kramer M, Schulze PE (1967) Absorption, distribution and elimination of labeled dimethyl sulfoxide in man and animals. Ann NY Acad Sci 141: 85-95.

2. Evans MS, Reid KH, Sharp JB (1993) Dimethyl sulfoxide (DMSO) blocks conduction in peripheral nerve $C$ fibers: A possible mechanism of analgesia. Neurosci Lett 150: 145-148. 
Citation: Gupta SRN (2016) Effect of Maxima Suppressor and Supporting Electrolyte on Polarographic Wave of Dimethyl Sulfoxide and its Determination. Med chem 6: 053-057. doi:10.4172/2161-0444.1000324

3. Demos CH, Beckloff GL, Donin MN, Oliver PM (1967) Dimethyl sulfoxide in musculoskeletal disorders. Ann NY Acad Sci 141: 517-523.

4. Lockie LM, Norcross BM (1967) A clinical study on the effects of dimethyl sulfoxide in 103 patients with acute and chronic musculoskeletal injuries and inflammations. Ann NY Acad Sci 141: 599-602.

5. Percy EC, Carson JD (1981) The use of DMSO in tennis elbow and rotator cuff tendonitis: a double-blind study. Med Sci Sports Exerc 13: 215-219.

6. Itoh M, Guth PH (1985) Role of oxygen-derived free radicals in hemorrhagic shock-induced gastric lesions in the rat. Gastroenterology 88: 1162-1167.

7. Salim AS (1992) Role of oxygen-derived free radical scavengers in the management of recurrent attacks of ulcerative colitis: a new approach. J Lab Clin Med 119: 710-717.

8. Santos L, Tipping PG (1994) Attenuation of adjuvant arthritis in rats by treatment with oxygen radical scavengers. Immunol Cell Biol 72: 406-414.

9. Matsumoto $\mathrm{J}$ (1967) Clinical trials of dimethyl sulfoxide in rheumatoid arthritis patients in Japan. Ann NY Acad Sci 141: 560-568.

10. De la Torre JC (1971) Modifications of experimental spinal cord injuries using dimethyl sulfoxide. Trans Am Neurol Assoc 97: 230.

11. De la Torre JC, Rowed DW, Kawanaga HM, Mullan S (1973) Dimethyl sulfoxide in the treatment of experimental brain compression. J Neurosurg 38: 345-354.
12. de la Torre JC, Kawanaga HM, Johnson CM, Goode DJ, Kajihara K, et al. (1975) Dimethyl sulfoxide in central nervous system trauma. Ann NY Acad Sci 243: 362-389.

13. Lawrence HJ, Goodnight SH Jr (1983) Dimethyl sulfoxide and extravasation of anthracycline agents. Ann Intern Med 98: 1025.

14. Lebredo L, Barrie R, Woltering EA (1992) DMSO protects against adriamycininduced tissue necrosis. J Surg Res 53: 62-65.

15. Alberts DS, Dorr RT (1991) Case report: topical DMSO for mitomycin-Cinduced skin ulceration. Oncol Nurs Forum 18: 693-695.

16. Cruse CW, Daniels S (1989) Minor burns: treatment using a new drug delivery system with silver sulfadiazine. South Med J 82: 1135-1137.

17. Miller L, Hansbrough J, Slater H, Goldfarb I, Kealey P, et al. (1990) Sildimac: A new deliver system for silver sulfadiazine in the treatment of full-thickness burn injuries. J Burn Care Rehab 11: 35-41.

18. Yang J, Yang G, Yang J (2011) Study on the analysis and distribution of dimethylsulfoxide in the Jiaozhou Bay. Acta Oceanol Sin 30: 36-45.

19. Sarah B, Phil P, George L (2011) Meta-Analysis of the Related Nutritional Supplements Dimethyl Sulfoxide and Methylsulfonylmethane in the Treatment of Osteoarthritis of the Knee. Evidence-Based Complementary and Alternative Medicine 2011: 528403. 